\section{Re-evaluating carbamazepine prophylaxis in bipolar disorder}

\author{
ROBERT M. POST, KIRK D. DENICOFF, MARK A. FRYE \\ and GABRIELE S. LEVERICH
}

The recent meta-analysis of Dardennes et al (1995) and a previous letter in the Lancet (Murphy et al, 1989), both concerning carbamazepine in bipolar affective disorder, suggest there are inadequate data, on the basis of the several studies reviewed, to support the claim that carbamazepine has prophylactic efficacy in the treatment of bipolar illness. While this suggestion may be correct based on the limited data selected for inspection and discussion, a wealth of other data more strongly suggest the clinical efficacy of carbamazepine in the acute and prophylactic treatment of bipolar patients.

Carbamazepine is approved in 107 countries for use in affective illness, yet the only drug approved in the USA by the Food and Drug Administration (FDA) for longterm prophylaxis in bipolar illness is lithium carbonate (although valproate has just been approved for the treatment of acute mania).
There is increasing recognition that up to $50 \%$ or more of patients with bipolar illness are inadequately responsive to long-term lithium treatment (O'Connell et al, 1991; Vestergaard, 1992). Thus, the clinician is obligated to find treatment alternatives, even among drugs not yet approved for bipolar illness, such as carbamazepine.

\section{ADDITIONAL SUPPORTING EVIDENCE OF CARBAMAZEPINE EFFICACY}

We have summarised in Table 1 at least 14 controlled or partially controlled studies of carbamazepine in long-term prophylaxis. While some of these studies utilise very different types of statistical designs, and have been criticised for their methodological and statistical flaws (Prien \& Gelenberg, 1989; Dardennes et al, 1995), as a whole they are strongly supportive of the efficacy of carbamazepine in the affective disorders.

Table I Controlled and partially controlled studies of carbamazepine (CBZ) and oxcarbazepine prophylaxis in affective illness

\begin{tabular}{|c|c|c|c|c|c|c|}
\hline \multirow[t]{2}{*}{ Study } & \multirow[t]{2}{*}{ Design } & \multirow[t]{2}{*}{ Placebo } & \multicolumn{2}{|r|}{ CBZ responders } & \multicolumn{2}{|c|}{ Lithium responders } \\
\hline & & & $n$ & $\%$ response & $n$ & $\%$ response \\
\hline Ballenger \& Post (1978) & Double-blind, mirror image & & $6 / 7$ & 86 & $(-)$ & $(-)$ \\
\hline \multicolumn{7}{|l|}{ Post et al (1983) } \\
\hline Okuma et al (1981) & Double-blind & $2 / 9$ & $6 / 10$ & 60 & $(-)$ & $(-)$ \\
\hline Svestka et al (1985) & Randomised & & $14 / 24$ & 62 & $12 / 24$ & 50 \\
\hline Kishimoto \& Okuma (1986) & Cross-over & & $(-) / 18$ & $\begin{array}{l}\text { Fewer hospitalisations } v \text {. } \\
\text { lithium }\end{array}$ & $(-)$ & $(-)$ \\
\hline Cabrera et al (1986)' & Randomised & & $2 / 4$ & 50 & $3 / 6$ & 50 \\
\hline Placidi et al (1986) & Double-blind, randomised & & $21 / 29$ & 72 & $20 / 27$ & 74 \\
\hline Watkins et al (1987) & Double-blind, randomised & & $16 / 19$ & 84 & $15 / 18$ & 83 \\
\hline Elphick et ol (1988) & Double-blind, randomised & & $3 / 8$ & 37 & $8 / 11$ & 73 \\
\hline Lusznat et al (1988) & Double-blind, randomised & & $(-) / 9$ & Fewer depressive episodes & $(-) / 5$ & $(-)$ \\
\hline Bellaire et al (1990) & Randomised & & $34 / 40$ & 85 & $42 / 49$ & 86 \\
\hline Di Costanzo \& Schiffano (1991) & Randomised ${ }^{2}$ & & $(-) / 16$ & $\begin{array}{l}\text { Fewer depressive episodes } \\
\text { with lithium }+C B Z \text { than } \\
\text { lithium alone }\end{array}$ & $(-) / 16$ & $(-)$ \\
\hline Mosolov (1991) & Randomised & & $(-) / 30$ & $58^{3}$ & $(-) / 30$ & 54 \\
\hline Coxhead et ol (1992) & Double-blind, randomised & & $7 / 15$ & 47 & $7 / 16$ & 44 \\
\hline $\begin{array}{l}\text { Denicoffet al (unpublished } \\
\text { observations) }\end{array}$ & Double-blind, randomised & & $11 / 35$ & 31 & $14 / 42$ & 33 \\
\hline $\begin{array}{l}\text { All controlled/partly controlled } \\
\text { studies }\end{array}$ & & & $120 / 191$ & 63 & $121 / 193$ & 63 \\
\hline All open studies & & & $390 / 629^{4}$ & 62 & & \\
\hline
\end{tabular}


Moreover, the data in these controlled or partially controlled studies, either doubleblind or randomised, indicate that $63 \%$ of patients show moderate to marked response, similar to the $62 \%$ response rate in the more substantial open clinical trial literature. Prien \& Gelenberg (1989) also indicated that the parallel design studies of Placidi et al (1986), Watkins et al (1987) and Lusznat et al (1988) utilised in the assessment of carbamazepine efficacy were flawed and less convincing than some other types of studies. Prien \& Gelenberg (1989) and Grof (1994) suggest that mirror-image designs in treatment-refractory patients, and other double-blind designs using on-off-on methodologies, do in fact support the efficacy of carbamazepine.

For example, in our double-blind studies with carbamazepine, we documented repeated clinical improvement during long periods of blind carbamazepine administration; exacerbation of mania, psychosis and time in seclusion with placebo substitution; and renewed response with blind carbamazepine re-institution (Ballenger \& Post, 1978; Post et al, 1983; 1984). The mirror-image design used in our later report (Post et al, 1990) also indicates that in many treatmentrefractory patients, carbamazepine used alone or as an adjunct to previously ineffective medications (Denicoff et al, 1994) can make a notable difference in patients' clinical course, although some patients do show loss of response to carbamazepine (or the other mood stabilisers, lithium and valproate) during longterm follow-up in a pattern resembling tolerance (Post et al, 1990; 1996, in press).

Elsewhere, we have summarised data from 19 double-blind studies utilising several types of designs (Post et al, 1996, in press) supporting the acute anti-manic efficacy of carbamazepine or its ketocongener oxcarbazepine. In our studies and those of six others, carbamazepine showed generally comparable magnitude, time-course and percentage of response to those of neuroleptics. Moreover, in our series, 18 of 19 patients receiving a second double-blind clinical trial of carbamazepine at the NIMH using a placeboactive-placebo-active design showed an adequate response during the second trial (Post et al, unpublished data), further confirming the initial observations of clinical efficacy using on-off-on designs. The question of whether carbamazepine is effective in the treatment of some patients with affective disorders can thus be answered more affirmatively on the basis of this additional literature.

\section{RESPONSIVE SUBGROUPS:THE IMPORTANCE OF IDENTIFYING PREDICTORS OF RESPONSE}

The more important questions would now be the response rate to carbamazepine in different clinical subgroups, and whether individual clinical or biochemical markers could be used to predict or increase the likelihood of response. For example, preliminary evidence suggests that a pattern of cerebral hypermetabolism (particularly in the temporal lobes), but not the more typical frontal hypometabolism pattern in depression, is associated with antidepressant response to carbamazepine (Ketter et al, 1996). If provided with better estimates of likelihood of response, the clinician could more accurately assess the risk:benefit ratio of using carbamazepine for the treatment of bipolar illness, which, if inadequately treated, carries a lifetime mortality rate from suicide of $10-20 \%$. In contrast, serious side-effects of carbamazepine, such as agranulocytosis and aplastic anaemia, have been estimated to occur in only 1 in 10 000-120 000 patients (Pellock, 1987).

\section{IMPLICATIONS FOR CLINICAL THER APEUTICS}

A similar argument could be made for the clinical use of the mood-stabilising anticonvulsant valproate in prophylaxis of refractory bipolar patients. While there are virtually no controlled studies of this drug's long-term efficacy, a substantial clinical literature using open studies suggests that it does have important effects in preventing manic and depressive recurrences in patients with rapid cycling and other extremely refractory presentations, including those patients with dysphoric mania (Emrich et al, 1980; Lambert, 1984; McElroy et al, 1992; Calabrese et al, 1993; Jacobsen, 1993; Schaff et al, 1993). These complement the controlled studies in acute mania leading to the FDA's approval of valproate for this indication (Bowden et al, 1994).

Here the interpretation of Dardennes et al (1995) regarding carbamazepine becomes crucial for clinical therapeutics. Are Dardennes et al suggesting that, because carbamazepine has not met their preselected criteria for efficacy, this agent should not be used in the treatment of recurrent bipolar disorder based on the available evidence? We would submit, on the contrary, that continued use of the approved drug lithium as the only moodstabilising drug approach to patients not adequately responsive to it, would constitute a grievous clinical error. These clinical considerations should, perhaps, be integrated with the opinion that while one type of pre-selected clinical trial methodology has failed to meet one academic standard for the demonstration of efficacy (although other types of designs have unequivocally demonstrated efficacy within individual patients: Ballenger \& Post, 1978; Post et al, 1983; 1984; 1990), promising treatments should not be withheld from patients on the basis of this partial approach to the available data. This opinion would be in accordance with the 1994 American Psychiatric Assocation guidelines for treatment of bipolar illness (Hirschfeld et al, 1994) and with most other clinical review panels and authorities in the field.

Hopefully, the academic aspects of this argument will be used not to limit treatment options but to propel further studies of not only the efficacy of the range of mood stabilisers in bipolar illness, but also of their optimal selection based on patients' clinical and biological presentations, and their appropriate application to clinical therapeutics in both monotherapy and rational combination therapy.

\section{REFERENCES}

Ballenger, J.C. \& Post, R. M. (1978) Ther apeutic effects of carbamazepine in affective illness: A preliminary report. Communications in Psychopharmacology, 2. 159- 175.

Bellaire, W., Demisch, K. \& Stoll, K.-D. (1990)

Carbamazepine vs. lithium. Application in the prophylaxis of recurrent affective and schizoaffective psychoses. Munch Med Wschr, 132. S82-S86.

Bowden, C. L., Brugeser, A. M., Swann, A. C., et al (1994) Efficacy of divalproex vs lithium and placebo in the treatment of mania. Journal of the American Medical Associotion. 271. 918-924.

Calabrese, J. R., Woyshwille, M. J., Kimmel, S. E., ex of (1993) Predictors of valproate response in bipolar rapid cycling. Journal of Clinical Psychopharmacology, 13. 280-283.

Cabrera, J. F., Muhbauer, H. D., Schloy, J., ot of (1986) Long-term randomized clinical trial on oxcarbazepine vs. lithium in bipolar and schizoaffective disorders: preliminary results. Pharmacopsychiatry. 19, 282-283.

Dardennes, R., Even, C., Bange, F., et ol (1995) Comparison of carbamazepine and lithium in the prophylaxis of bipolar disorders. A meta-analysis. British journal of Psychiatry. 166. 378-381

Denicoff, K. D., Blake, K. D., Smith-jackson, E. E., et of (1994) Morbidity in treated bipolar disorder: a one-year 
prospective study using dally life chart ratings. Depression, 2 $95-104$

Di Costanzo, E. Schifano, F. (1991) Lithium alone or in combination with carbamazepine for the treatment of rapid cycling bipolar affective disorder. Acto Psychiatrico Scandinavico. 83. 456-459.

Elphick, M., Lyons, F. Cowen, P. J. (1988) Low tolerability of carbamazepine in psychiatric patients may restrict its clinical usefulness. Journal of Psychopharmacology, 2. 1-4

Emrich, H. M., Von Zerssen, D., Kissling, W., et al (1980)

Effect of sodium valproate in mania. The GABA hypothesis of affective disorders. Arch Psychiatr Nervenkr. 229. 1- 16.

Grof, P. (1994) Designing long-term clinical trials in affective disorders. Journal of Affective Disorders. 30. 243-255.

Hirschfold, R. M. A., Clayton, P., Cohen, I., et ol (1994) American Psychiatric Association practice guidelines for bipolar disorder. American journal of Psychiatry. I5I (suppl.). $1-36$

Jacobsen, F. M. (1993) Low-dose valproate: A new treatment for cyclothymia, mild rapid cycling disorders, and premenstrual syndrome. journal of Clinical Psychiatry. 54 229-234

Kotter, T. A., Kimbrell, T. A., George, M. S., et al (1996) Baselıne hypermetabolism may predict carbamazepine response, and hypometabolism nimodipine response in mood disorders. Abstracts of the 20th CINP Congress. 10 (abstract 0.5-6)

Kishimoto, A. Okuma, T. (1986) Antimanic and prophylactic effects of carbamazepine in affective disorders. In Bıological Psychiotry (eds C. Shagas, R. C. Josiassen, W. H Bridger, et al), pp. 883-885. Amsterdam: Elsevier.

Lambert, P. A. (1984) Acute and prophylactic therapies of patients with affective disorders using valpromide (dipropylacetamide). In Anticonvulsonts in Affective Disorders (eds H. M. Emrich. T. Okuma \& A. A. Muller). pp. 33-44. Amsterdam: Exerpta Medica.

Lusznat, R. M., Murphy, D. P. \& Nunn, C. M. H. (1988) Carbamazepine vs. lithium in the treatment and prophylaxis of mania. British journol of Psychiatry. 153. 198-204.
McElroy, S. L., Keck, P. E., Pope, H. G., et al (1992) Valproate in the treatment of bipolar disorder: Literature review and clinical guidelines. Journal of Clinical sychophormacology. 12 (suppl. 1). 42S-52S.

Mosolov, S. N. (1991) Comparative effectiveness of preventive use of lithium carbonate, carbamazepine and sodium valproate in affective and schizoaffective psychoses. Zhurnal Nevropatologi I Psikhiatru Imenı S. S. Korsakovo (Moskvo), 91. 78-83.

Murphy, D. J., Gannon, M. A. \& McGennis, A. (1989) Carbamazepine in bipolar affective disorder (letter). Lancet, " $1151-1152$

O'Connell, R. A., Major, J. A., Flatlow, L., et al (1991) Outcome of bipolar disorder on long-term treatment with lithium. British journal of Psychiotry. 159. 123-129.

Okuma, T., Inanaga, K., Otsuke, S., et al (1981) A preliminary double-blind study of the efficacy of carbamazepine in prophylaxis of manic-depressive illness. Psychopharmocology. 73. 95-96.

Pellock, J. M. (1987) Carbamazepine side effects in children

Placidi, G. F., Lenzi, A., Lazzerini, F., ot al (1986) The comparative efficacy and safety of carbamazepine versus lithium: A randomized, double-blind 3-year trial in 83 patients. Journal of Clinical Psychiotry, 47. 490-494.

Post, R. M., Uhde, T. W., Ballenger, J. C., et al (1983)

Prophylactic efficacy of carbamazepine in manic - depressive illness. American Journal of Psychiatry. 140. 1602-1604 and adults. Epilepsıa. 28 (suppl. 3), 564-570.
_, Berrettini, W. H., Uhde, T. W., et al (1984) Selective response to the anticonvulsant carbamazepine in manicdepressive Illness: A case study. Journal of Clinical Psychopharmacology, 4. 178-185.

\section{_ , Leverich, G. S., Rosoff, A. S., et al (1990)}

Carbamazepine prophylaxis in refractory affective disorders: A focus on long-term follow-up. Journal of Clinical Psychopharmacology. 10. 318-327.

_, Ketter, T. A., Pazzaglia, P. J., et al (1996) Rational polypharmacy in the bipolar affective disorders. Epilepsy Research, in press.

Prien, R. F. \& Gelenberg, A. J. (1989) Alternatives to lithium for preventive treatment of bipolar disorder. American journal of Psychiatry, 146. 840-848.

Schaff, M. R., Fawcett, J. \& Zajecka, J. M. (1993) Divalproex sodium in the treatment of refractory affective disorders. Journal of Clinical Psychiatry. 54. 380-384.

Svetska, J., Nahunek, K., Ceskova, E., ot al (1985) Carbamazepine prophylaxis of affective psychoses (intraindividual comparison with lithium carbonate). Activ Nerv Sup. 27. $261-262$.

Vestergaard, P. (1992) Treatment and prevention of mania: A Scandinavian perspective. Neuropsychopharmacology. 7. $249-260$

Watkins, S. E., Callender, K., Thomas, D. R., et al (1987) The effect of carbamazepine and lithium on remission from affective illness. British journal of Psychiatry, 150. 180-182
ROBERT M. POST, KIRK D. DENICOFF, MARK A. FRYE, GABRIELE S. LEVERICH, Biological Psychiatry Branch, National Institute of Mental Health, Bethesda, Maryland, USA

Correspondence: Dr Robert M. Post. Chief, Biological Psychiatry Branch, NIMH. Building 10, Room 3N212, 10 Center Drive, MSC 1272, Bethesda, MD 20892-1272, USA

(First received 10 June 1996, final revision 30 September, accepted 10 October 1996) 